\title{
Experimental Measurement of Specific Impulse Distribution and Transient Deformation of Plates Subjected to Near-Field Explosive Blasts
}

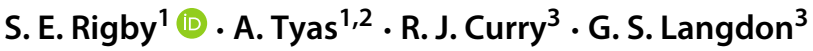

Received: 31 May 2018 / Accepted: 3 October 2018 / Published online: 4 December 2018

(C) The Author(s) 2018

\begin{abstract}
The shock wave generated from a high explosive detonation can cause significant damage to any objects that it encounters, particularly those objects located close to the source of the explosion. Understanding blast wave development and accurately quantifying its effect on structural systems remains a considerable challenge to the scientific community. This paper presents a comprehensive experimental study into the loading acting on, and subsequent deformation of, targets subjected to nearfield explosive detonations. Two experimental test series were conducted at the University of Sheffield (UoS), UK, and the University of Cape Town (UCT), South Africa, where blast load distributions using Hopkinson pressure bars and dynamic target deflections using digital image correlation were measured respectively. It is shown through conservation of momentum and Hopkinson-Cranz scaling that initial plate velocity profiles are directly proportional to the imparted impulse distribution, and that spatial variations in loading as a result of surface instabilities in the expanding detonation product cloud are significant enough to influence the transient displacement profile of a blast loaded plate.
\end{abstract}

Keywords Digital image correlation · Hopkinson pressure bar · Near-field blast · Plate deformation · Specific impulse

\section{Introduction}

When a blast wave interacts with a structure located close to the source of the explosive, the resulting transient blast load is extremely high magnitude, short duration, and highly spatially non-uniform over the face of the target. A considerable challenge to the blast protection community is to understand and control the risks associated with accidental or malicious blast events, and design adequate protective systems to mitigate their effects. Clearly, this

S. E. Rigby

sam.rigby@shef.ac.uk

1 Department of Civil \& Structural Engineering, University of Sheffield, Mappin Street, Sheffield, S1 3JD, UK

2 Blastech Ltd., The BioIncubator, 40 Leavygreave Road, Sheffield, S3 7RD, UK

3 BISRU, Department of Mechanical Engineering, University of Cape Town, Rondebosch 7700, Republic of South Africa requires intimate knowledge of both the loading imparted to the target, and the transient response of the system itself.

This paper presents a combined experimental study into the specific impulse distribution and resultant transient plate deformation arising from the interaction of a near-field explosive detonation with a target plate. Experimental tests at the University of Sheffield (UoS), UK, measured the spatial and temporal distribution of pressure and specific impulse resulting from the detonation of spherical and cylindrical charges close to the surface of a nominally rigid target plate. Similar scaled experiments were conducted at the Blast Impact \& Survivability Unit (BISRU) at the University of Cape Town (UCT), South Africa, to measure the transient deformation of circular plates exposed to nearfield explosive blasts. The two sets of experimental data are used to make comments on the form and magnitude of the blast load and resultant plate displacements, and serve as comprehensive validation data for subsequent numerical analyses. Crucially, this two-stage approach allows for validation of both the loading model and resultant structural deformation, allowing us to make comments on the accuracy and veracity of the proposed numerical methods for each stage: loading and deformation. 


\section{Background}

\section{Literature Review}

A detailed history of early air-blast experimentation, particularly from the second world war onwards, can be found in Esparza [1]. The data from many of these early studies would later be compiled to form the now wellestablished Kingery and Bulmash (KB) semi-empirical blast predictive method [2]. Close to the charge, direct measurements of the blast parameters were either "nonexistent or very few" [1] and the near-field semi-empirical predictive data were inferred from non-direct measurements [3] or rudimentary numerical analyses [4]. Whilst KB blast parameter predictions have been shown to be accurate for far-field, geometrically simple scenarios [5], there is currently a lack of definitive experimental validation data in the extreme near-field (a few radii from the centre of the charge). As such, there remains a great level of uncertainty on the exact form and magnitude of the loading imparted to a target located close to the source of an explosion, as highlighted in the modelling work of Shin et. al [6] where differences of $>400 \%$ were reported between the numerical and predicted reflected pressure at short distances from the explosive.

Since the development of the KB predictive method there have been efforts to experimentally measure the blast load in extreme near-field conditions. One method involves measuring the residual momentum of - and hence inferring the impulse imparted to - small, rigid metal plugs embedded within a larger target surface [7, 8], however this approach cannot be used to give a temporal description of the blast load. An alternative, developed in 1914 by Bertram Hopkinson, is the apparatus now known as the Hopkinson pressure bar (HPB) [9], consisting of a length of cylindrical bar which propagates an elastic stress pulse along its axis to be recorded by sensitive equipment situated a safe distance from the loaded end. Whilst it is now more commonly used in its 'split' form for high strain-rate material testing [10], the HPB is still a valuable tool for measuring highmagnitude, short-duration loading [11-16]. HPBs are used in this study at UoS to record the spatial and temporal distribution of loading acting on a rigid target located close to an explosive.

There is a large body of experimental work on the dynamic response of plates subjected to large dynamic loading arising from blast and impact events. Typically the primary metric used to assess plate performance under extreme loading is some measure of peak dynamic or residual deformation at the centre of the plate [17-27]. Whilst this information may enable researchers to develop relationships between basic parameters, it is often more desirable for validation of numerical modelling approaches to have a more detailed description of the transient displacement profile of the plate. Digital image correlation (DIC) was first introduced in 1983 [28] and has recently been used to more accurately study fullfield transient deformations of blast loaded plates [29-42].

It is clear that whilst the topics of loading and deformation have been studied more extensively in recent years, our knowledge of exactly how the blast load develops on the loaded face and subsequently drives the displacement of a target plate is still inhibited by a lack of repeatable and well-controlled experimental data. There is a need, therefore, to present a combined study into the detailed measurement of blast loading and target deformation from extremely near-field blast events.

\section{Hopkinson-Cranz Scaling}

Hopkinson-Cranz scaling [43, 44] is based on fundamentals of geometrical similarity and can be used to relate the blast parameters from one set of physical experiments (or simulations) to another set conducted at a different scale. Two explosions can be expected to give identical blast waves ${ }^{1}$ at distances which are proportional to the cube-root of the respective energy release [45], i.e. the blast pressure profile at a distance of $R$ from an explosive mass $W$ will be similar to the blast pressure at a distance of $K R$ from a mass of $K^{3} W$. The scaled distance of a blast event, therefore, is defined as the distance from the blast divided by the cuberoot of the charge mass, i.e. $Z=R / \sqrt[3]{W}$. It can be seen that the two examples described previously will have an identical scaled distance,

$$
\frac{R}{\sqrt[3]{W}}=\frac{K R}{\sqrt[3]{K^{3} W}}=Z
$$

Pressures and velocities do not change between scales, however arrival times, durations and impulses are scaled by the length scale factor, $K$. The Kingery and Bulmash predictive method [2], for example, utilises a form of HopkinsonCranz scaling to present scaled distance-parameter relationships, where scaled and de-scaled pressure parameters are identical, and arrival times, durations and impulses are scaled by the cube-root of the charge mass. In this study, the principles of Hopkinson-Cranz scaling are used to compare the results from blast experiments conducted at different length scales but with identical scaled geometries.

\section{Experimental Setup}

\section{'Characterisation of Blast Loading' Apparatus}

Blast load distributions were measured in experiments conducted at the University of Sheffield Blast \& Impact

\footnotetext{
${ }^{1}$ Assuming identical charge shapes and ambient conditions
} 
Fig. 1 Schematic of UoS testing apparatus [not to scale]: (a) elevation; (b) detailed plan view of target plate showing bar arrangement and coordinate axes (adapted from [48])
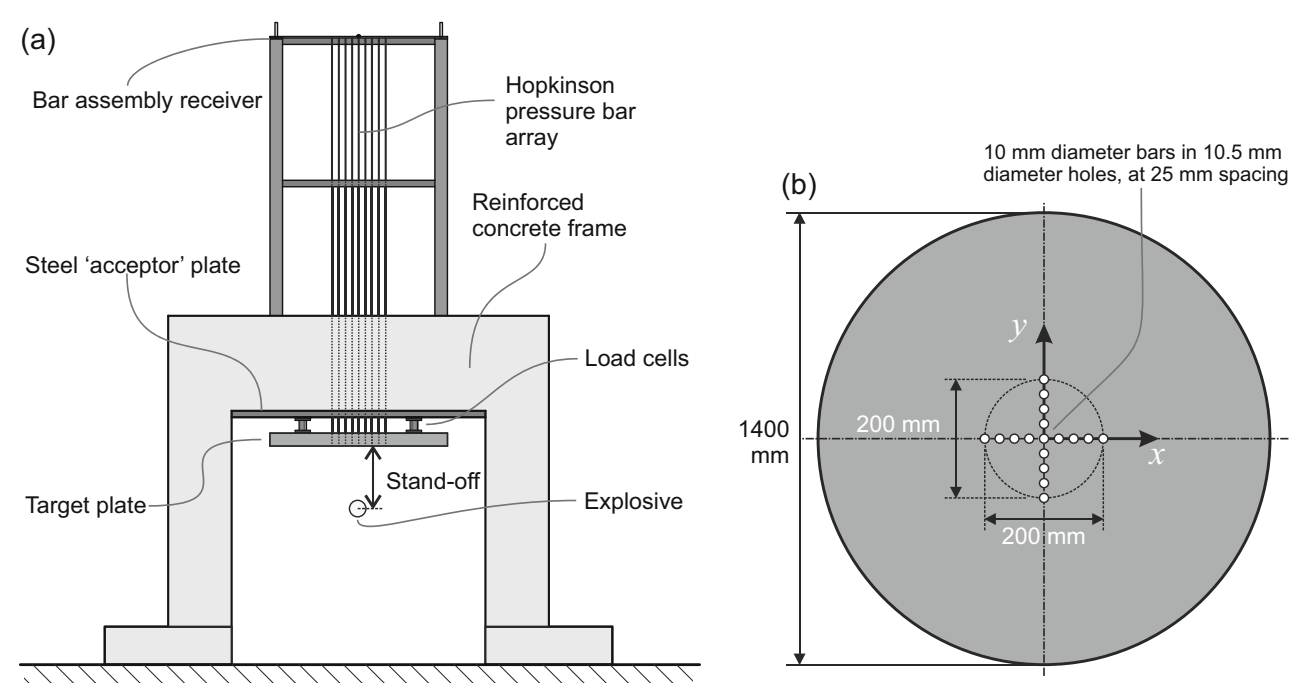

Laboratory in Buxton, UK, using the Characterisation of Blast Loading (CoBL) apparatus [46]. The CoBL apparatus, shown in Fig. 1(a), comprises a pair of stiff, massive, fibre and bar reinforced concrete frames spaced $1 \mathrm{~m}$ apart, with each frame comprising two $500 \mathrm{~mm}$ square columns with a $750 \mathrm{~mm}$ deep, $500 \mathrm{~mm}$ wide concrete beam spanning horizontally between the two columns. A $100 \mathrm{~mm}$ thick steel target plate is underslung from the soffits of the horizontal beams and acts as a nominally rigid boundary to reflect the shock wave and detonation products impinging on the target after detonation of an explosive some distance beneath the centre of the plate. The plate is $1.4 \mathrm{~m}$ in diameter to negate the effect of blast wave clearing around the target edge [47].

The target plate is drilled through its thickness to allow $10 \mathrm{~mm}$ diameter, $3.25 \mathrm{~m}$ long EN24(T) steel HPBs to be mounted and set with their loaded faces flush with the underside of the target plate. A total of 17 bars were used; one central bar and four bars located at each radial offset of 25, 50, 75 and $100 \mathrm{~mm}$ from the plate centre, with the bar naming convention in this article following the coordinate axes shown in Fig. 1(b).

Kyowa KSP-2-120-E4 semi-conductor strain gauges were mounted in pairs on the perimeter of each HPB at $250 \mathrm{~mm}$ from the loaded face, in a Wheatstone-bridge circuit to neglect any bending effects and to ensure that only the axial strain component was recorded. Strain data were recorded using 14-Bit digital oscilloscopes at a sample rate of $3.125 \mathrm{MHz}$ and were triggered via a voltage drop in a separate breakwire channel.

\section{Digital Image Correlation Pendulum}

Plate deformations and global impulse were measured in tests conducted at BISRU at the University of Cape Town. The blast pendulum described in Ref. [49], was recently modified to include stereo high speed video (HSV) capabilities [40]. The pendulum consists of an I-beam suspended from four cables with a clamping frame located at the front of the pendulum to constrain the test plates, and added counterbalance at the rear of the pendulum (Fig. 2). A mild steel shroud covers the pendulum to protect the cameras and lighting system housed within. Part of the web of the I-beam had been removed so as to not inhibit the cameras' view (and illumination) of the rear of the test plate. The cameras were positioned appropriately for the focal distance of the lenses selected, and were mounted on an extruded aluminium rail system which was sat on nylon blocks to reduce the transmission of vibration to the cameras.

The test plates were made from $400 \times 400 \times 3 \mathrm{~mm}$ thick Domex $355 \mathrm{MC}\left(7830 \mathrm{~kg} / \mathrm{m}^{3}\right)$, a high-strength, hot rolled, low alloy steel [40], with an exposed circular area of
Fig. 2 Schematic elevation of UCT testing apparatus [not to scale] (adapted from [40])

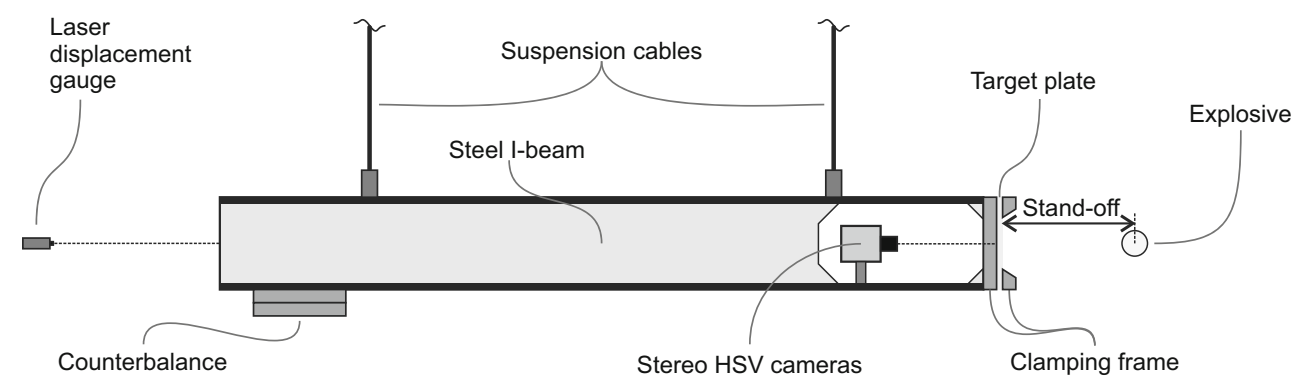


$300 \mathrm{~mm}$ diameter when loaded in the clamping frame. The plates were fully clamped around the perimeter, with constrained zero in-plane and out-of-plane displacement and constrained rotations at the boundary.

\section{Transient plate deformation measurements}

Digital image correlation (DIC) [28] was used to measure the transient deformation profile of the plates using two IDT vision NR4S3 high speed cameras. The cameras were separated at an included angle of approximately $30^{\circ}$ and were fitted with $35 \mathrm{~mm}$ fixed focus lenses. A field-ofview of $1024 \times 76$ pixels was selected in order to cover a full-width strip along the centreline of the plates (an approximate region of $300 \times 25 \mathrm{~mm}$ ). HSV data were recorded at 30,000 fps with the exposure set to $31 \mu \mathrm{s}$. The desired illumination was achieved with the use of two custom-built LED lights, focussed on the rear of the test plate. Light diffusers were used to ensure uniform illumination across the field-of-view of the cameras. The rear surface of each plate was first sprayed with a thin layer of white primer before a black speckle pattern was added, generating a random pattern for use in the DIC software. The rear surface of each plate was thoroughly cleaned, abraded, and degreased with acetone before painting to allow for better adhesion of the paint to the plate.

Dantec Dynamics Istra 4D DIC software was used to process the HSV data. Prior to each test a calibration target was filmed and the data was used to generate intrinsic and extrinsic calibration values for each test, ensuring consistent accuracy across the entire test series. These calibration values were then imported into the DIC software enabling full-field out-of-plane transient displacement profiles of the plate to be generated post-test. Further information on the DIC method used in the current testing is available in Ref. [40]. Data were extracted from a gauge line, defined in the software using a straight line drawn through the centreline of the test plate. The transient centreline displacements were then exported into MatLab for postprocessing. Any rigid body motion of the cameras and framing system was automatically removed from the processed results.

\section{Global impulse measurements}

The motion of the pendulum was recorded using a CP35MHT80 laser displacement sensor (50 $\mu \mathrm{m}$ resolution) which was focussed on the rear of the pendulum. Displacement data were recorded by a digital oscilloscope which was triggered by the initial movement of the pendulum and recorded at a sample rate of $100 \mathrm{kHz}$, which was found to be sufficient to fully capture the swing of the pendulum post detonation.

The impulse imparted to the test plate, $I$, is given as

$I=m v$

where $m$ is the mass of the pendulum, and $v$ is the initial velocity of the pendulum, calculated from

$v=\frac{2 \pi}{T} y_{1} e^{\frac{\beta T}{4}}$

where $T$ is the natural period of the system, taken as the average period under forced vibration measured separately before each test series, and $\beta$ is the damping coefficient which can be calculated from knowledge of the peak forwards displacement (in the direction of the blast), $y_{1}$, and peak backwards displacement (towards the source of the blast), $y_{2}$,

$\beta=\frac{2}{T} \ln \left(\frac{y_{1}}{y_{2}}\right)$.

The values of peak forwards and backwards displacement are determined for each test from a $5^{\text {th }}$-order polynomial curve fit to the recorded pendulum motion, with separate curves defined for forwards and backwards displacement cycles for greater accuracy.

\section{Explosive Charge Geometries and Test Plan}

Seventeen tests were conducted in total: seven tests using the CoBL apparatus, as detailed in the UoS test programme

Table 1 Summary of localised load measurement tests conducted at University of Sheffield

\begin{tabular}{llllllll}
\hline Test no. & $\begin{array}{l}\text { Charge } \\
\text { mass }(\mathrm{g}\end{array}$ & $\begin{array}{l}\text { Stand- } \\
\text { off from } \\
\text { charge } \\
\text { centre } \\
(\mathrm{mm})\end{array}$ & $\begin{array}{l}\text { Stand- } \\
\text { off from } \\
\text { charge } \\
\text { surface } \\
(\mathrm{mm})\end{array}$ & $\begin{array}{l}\text { Charge } \\
\text { radius } \\
(\mathrm{mm})\end{array}$ & $\begin{array}{l}\text { Charge } \\
\text { height } \\
(\mathrm{mm})\end{array}$ & $\begin{array}{l}\text { Explosive } \\
\text { shape }\end{array}$ & Casing \\
\hline $1-3$ & 100 & 80.0 & 55.4 & 24.6 & 49.2 & sphere & none \\
$4-6$ & 78 & 177.5 & 168.0 & 28.6 & 19.0 & $3: 1$ (d:h) cylinder & 3 mm PVC (lid removed) \\
7 & 78 & 177.5 & 168.0 & 28.6 & 19.0 & $3: 1$ (d:h) cylinder & none \\
\hline
\end{tabular}


Table 2 Summary of plate deformation/global impulse tests conducted at University of Cape Town

\begin{tabular}{|c|c|c|c|c|c|c|c|}
\hline Test no. & $\begin{array}{l}\text { Charge } \\
\text { mass (g } \\
\text { PE4) }\end{array}$ & $\begin{array}{l}\text { Stand- } \\
\text { off from } \\
\text { charge } \\
\text { centre } \\
(\mathrm{mm})\end{array}$ & $\begin{array}{l}\text { Stand- } \\
\text { off from } \\
\text { charge } \\
\text { surface } \\
(\mathrm{mm})\end{array}$ & $\begin{array}{l}\text { Charge } \\
\text { radius } \\
(\mathrm{mm})\end{array}$ & $\begin{array}{l}\text { Charge } \\
\text { height } \\
(\mathrm{mm})\end{array}$ & $\begin{array}{l}\text { Explosive } \\
\text { shape }\end{array}$ & Diagnostics \\
\hline 8,9 & 50 & 63.5 & 44.0 & 19.5 & 39.0 & sphere & impulse only \\
\hline 10,11 & 50 & 153.3 & 145.0 & 24.5 & 16.5 & 3:1 (d:h) cylinder & impulse only \\
\hline $12-14$ & 50 & 63.5 & 44.0 & 19.5 & 39.0 & sphere & impulse and DIC \\
\hline $15-17$ & 50 & 153.3 & 145.0 & 24.5 & 16.5 & 3:1 (d:h) cylinder & impulse and DIC \\
\hline
\end{tabular}

in Table 1; and ten tests using the digital image correlation pendulum, as detailed in the UCT test programme in Table 2.

\section{Charge masses}

PE4 explosive charges were used throughout. In tests $1-3$ at UoS, $100 \mathrm{~g}( \pm 0.05 \mathrm{~g})$ spherical PE4 explosive charges were hand-pressed into bespoke 3D-printed moulds, ensuring a consistent and regular spherical shape. In tests $4-7$ at UoS, 78 g PE4 charges were formed into cylinders with diameter:height ratio of 3:1 by hand-pressing them directly into $3 \mathrm{~mm}$ thick PVC containers with internal dimensions exactly matching the required dimensions of the charges. The charges in test 4-6 were kept in the PVC containers (consistent with previous testing [48]), and the charge in test 7 was removed from the container to provide comparative data on the container's influence on blast load development (see "Effect of charge casing").

In the UCT tests, $50 \mathrm{~g}( \pm 0.05 \mathrm{~g})$ PE4 chargers were handrolled into spheres (tests 8,9 , and 12-14), or hand-pressed into cylindrical moulds (tests 10, 11, and 15-17) with diameter:height ratio of 3:1 to match the geometry of the UoS tests. Each charge was measured with callipers after being shaped to ensure charge size consistency. Five tests were performed for each charge configuration: two commissioning tests without DIC, and three tests with DIC (Table 2).

Charge geometries and stand-off distances for the UCT tests were designed to be similar to UoS tests using Hopkinson-Cranz scaling ("Hopkinson-Cranz Scaling”).

\section{Charge placement}

The charges in tests $1-3$ were suspended directly under the centre of the target plate on a 'drumskin' comprising a glassfibre weave fabric (density $25 \mathrm{~g} / \mathrm{m}^{2}$ ) held taut in a steel ring, set on adjustable struts mounted in the base of the test arena. The charges in tests 4-7 were placed on a small timber prop, sat inside an empty steel container to match the geometry of previous testing with buried explosives $[48,50]$. The timber prop was machined to give the required stand-off between the charge surface and the target, and was $3 \mathrm{~mm}$ longer in test 7 to account for omission of the PVC case. In all UoS tests the charges were aligned with the plate centre using an alignment laser, and the clear stand-off distance from the charge surface to the plate $(55.4 \mathrm{~mm}$ tests $1-3$, $168.0 \mathrm{~mm}$ tests $4-7$ ) was measured and confirmed to be within tolerance $( \pm 0.5 \mathrm{~mm})$.

The UoS charges were detonated using Nitronel MS 25 non-electronic shock-tube detonators (700 mg PETN) inserted through the bottom face of the charge to a depth marked on the detonator corresponding to the charge radius (tests 1-3) or half charge height (tests 4-7). A breakwire was wrapped around the detonator to give an accurate reading of the time of detonation and hence serves as a trigger for the HPB channels.

In the UCT tests, the charges were affixed to a thin polystyrene bridge which spanned $250 \mathrm{~mm}$ onto polystyrene legs which were machined to the exact stand-off distance plus charge height, as the rear face of the explosives was attached to the polystyrene bridge so as to not obstruct the propagation of the blast wave between the charge and the target. The bridge legs were attached to the target plate using double-sided tape and were positioned according to markers drawn on the plate using a template to ensure consistent charge placement. M2A3 electric detonators were inserted through the polystyrene bridge into the centre of the charges from the rear, to ensure repeatable detonator placement which was consistent with the UoS tests (detonators were inserted to a depth equal to the charge radius in tests 8,9 , and 12-14, and a depth equal to half charge height in tests 10,11 , and 15-17). As with the UoS tests, the required insertion depth was marked on the detonator prior to placement to ensure consistency. A breakwire was formed using a thin strip of foil attached to the back of the polystyrene bridge which was used to trigger the cameras. Bare charges were used throughout, based on the negligible influence of the 
cylindrical charge casing as demonstrated in "Effect of charge casing".

\section{Results}

\section{Direct Load Measurements}

\section{Spherical charge tests}

Figure 3 shows example pressure-time and specific impulsetime histories from test 1 , for a single array of five pressure bars located at $0,25,50,75$, and $100 \mathrm{~mm}$ from the plate centre. The time datum of the recorded signals has had $50 \mu \mathrm{s}$ subtracted to account for the time taken for each stress pulse
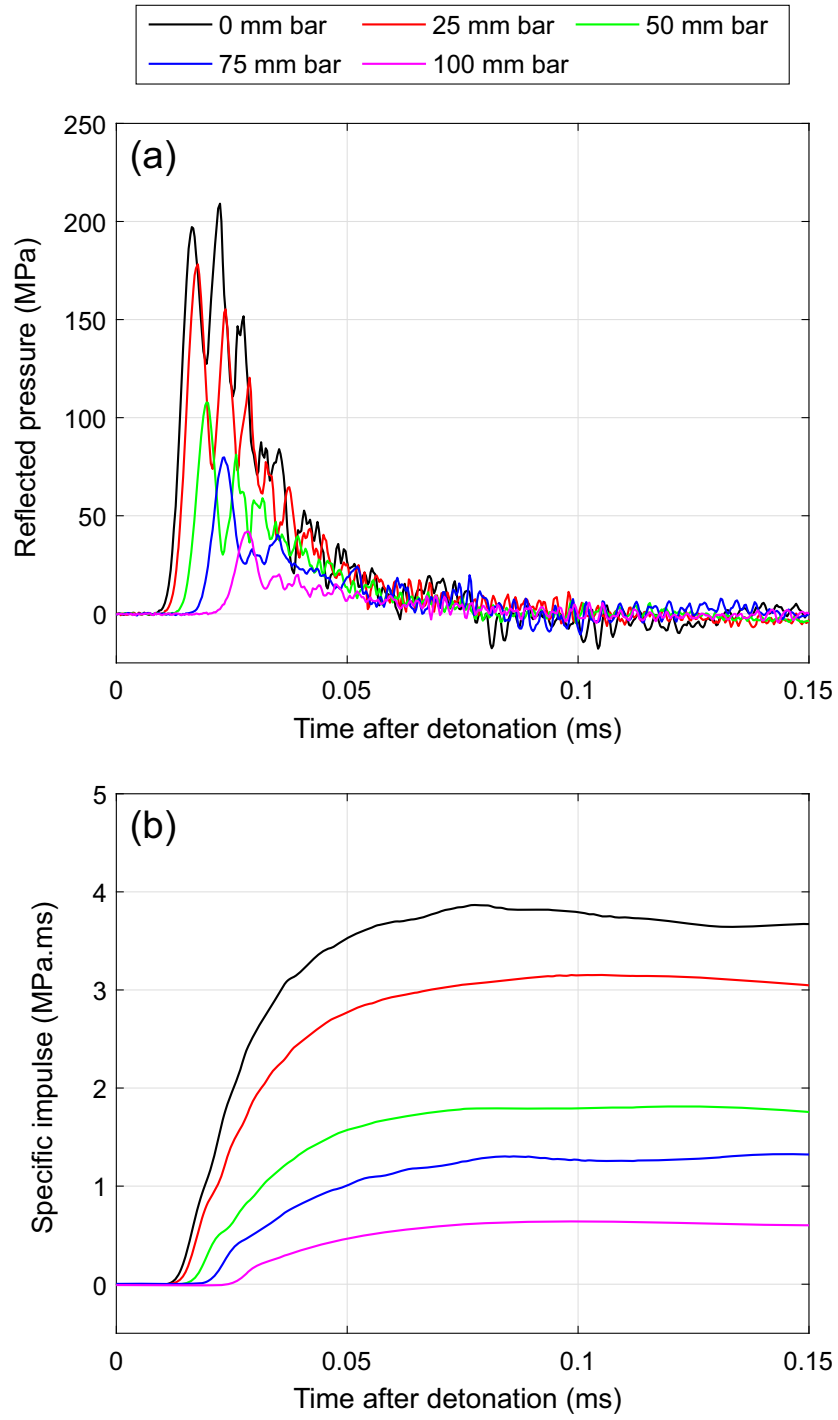

Fig. 3 (a) pressure-time, and (b) specific impulse-time histories for $+x$ array; Test 1 (100 g sphere at $55.4 \mathrm{~mm}$ clear stand-off) to reach the gauge location from the loaded face of the HPB. Aside from oscillations in the data caused by PochhammerChree dispersion [51], the blast pressures appear to resemble the characteristic 'Friedlander' waveform [52], in that there is a sudden rise to peak pressure followed by an exponential decay back to ambient conditions, with recorded positive phase durations of $\sim 0.05-0.07 \mathrm{~ms}$. As the blast event is located within the extreme near-field regime, negative phase effects are either negligible or non-existent [53].

Dispersion effects can be seen to 'round off' the leading edge of the stress pulse, with the peak pressure in the central $(0 \mathrm{~mm})$ bar occurring on the second oscillation, rather than with arrival of the stress pulse as is the case with all other bars. Some higher frequency components of the signal (which travel at a lower velocity relative
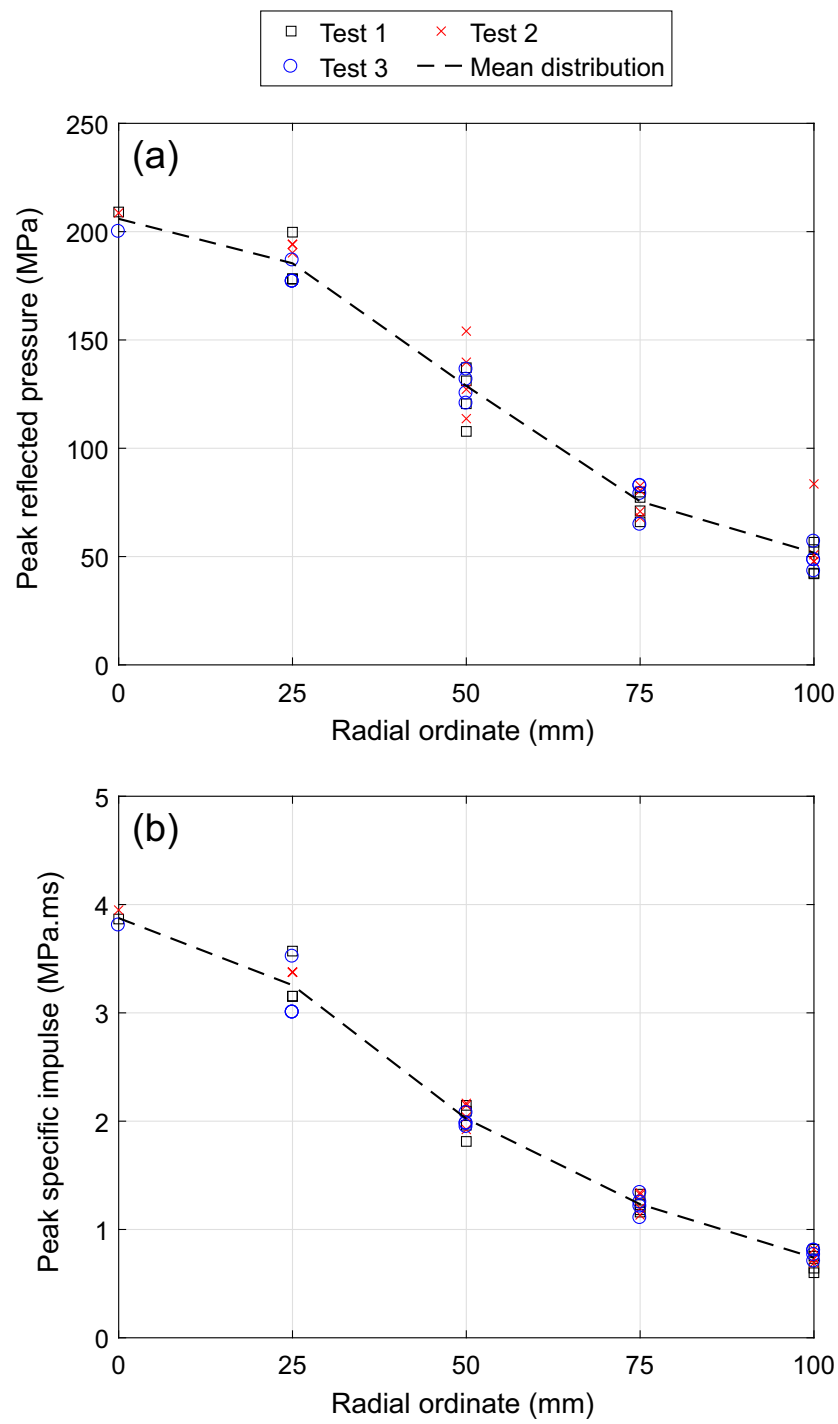

Fig. 4 (a) compiled peak pressure, and (b) compiled peak specific impulse at each bar location; Tests $1-3$ (100 g sphere at $55.4 \mathrm{~mm}$ clear stand-off) 
to the lower frequency components [54]) can be seen to arrive towards the end of the positive phase. Whilst this demonstrates that there may be significant high frequency features associated with the sharp rise of the pressure pulse, current frequency-domain dispersion correction methods are limited to frequencies of $250 \mathrm{kHz}$ [55] for the bar radii used in this study. Transients of $<4 \mu$ s therefore cannot yet be resolved and details of the blast load immediately following arrival of the shock wave cannot be extracted from the current measurement technique.

The specific impulse, determined from cumulative temporal integration of the pressure signals, is unaffected by dispersion, and decays from an epicentral value of 3.87 MPa.ms to a value of $0.82 \mathrm{MPa} . \mathrm{ms}$ at a radial offset of $100 \mathrm{~mm}$ (approximately 4 charge radii) from the plate centre.
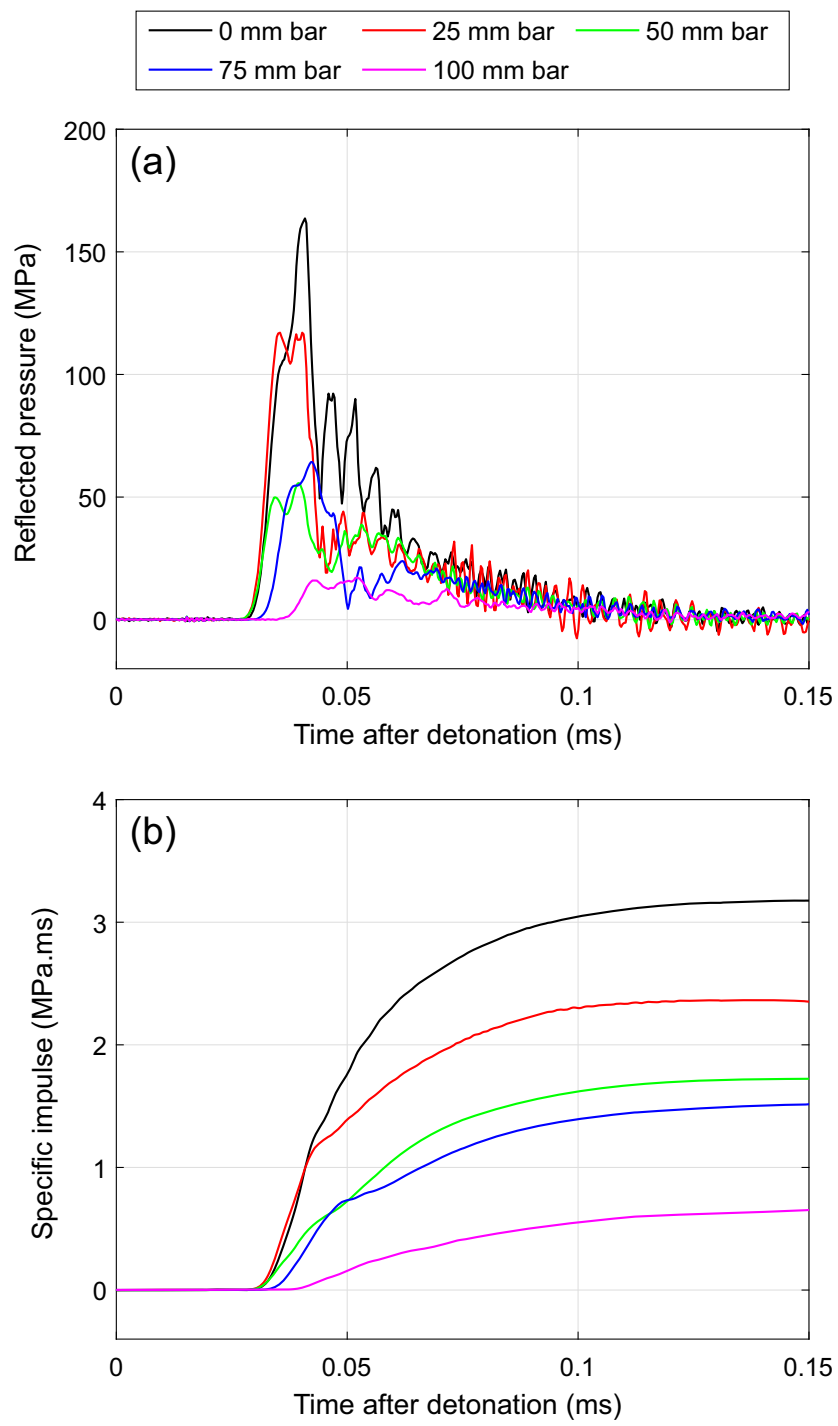

Fig. 5 (a) pressure-time, and (b) specific impulse-time histories for $+x$ array; Test 5 (78 $\mathrm{g} \mathrm{3:1} \mathrm{cylinder}$ at $168.0 \mathrm{~mm}$ clear stand-off)
Figure 4 shows the compiled peak pressure and peak specific impulse for tests $1-3$. Generally there is a good degree of test-to-test repeatability for this charge size and stand-off distance, with all values of peak pressure and peak specific impulse occupying a narrow band either side of the mean distribution.

\section{Cylindrical charge tests}

Figure 5 shows example pressure-time and specific impulsetime histories from test 5 , again with $50 \mu$ s subtracted from the time datum. Compiled peak pressure and peak specific impulse for tests 4-6 are shown in Fig. 6.

Generally, the compiled blast parameters for the cylindrical tests demonstrate a larger degree of variability when
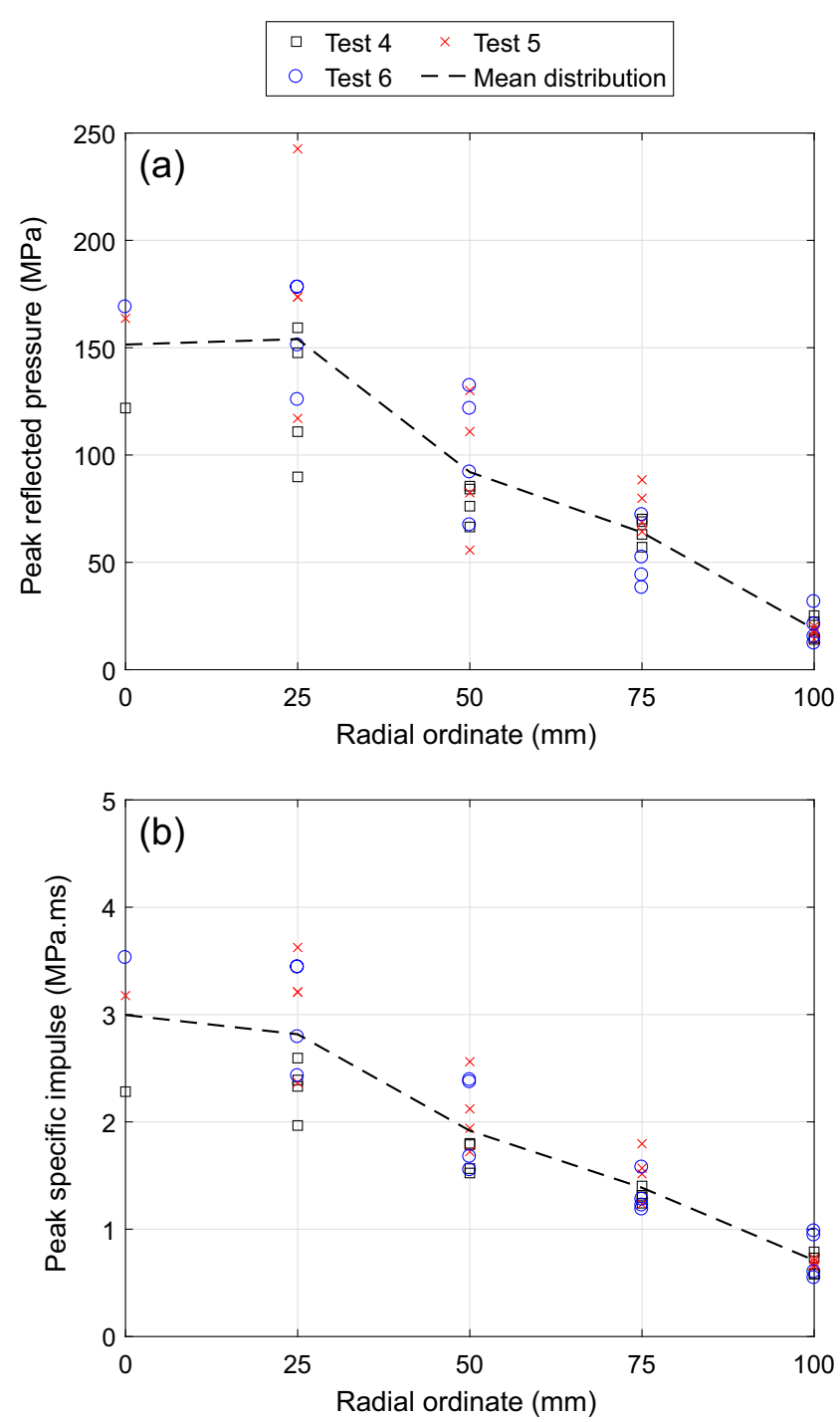

Fig. 6 (a) compiled peak pressure, and (b) compiled peak specific impulse at each bar location; Tests 4-6 (78 g 3:1 cylinder at $168.0 \mathrm{~mm}$ clear stand-off) 
compared with the spherical tests. For example, the $+y$ $25 \mathrm{~mm}$ bar in test 5 recorded a peak pressure of $243 \mathrm{MPa}$, which is $58 \%$ greater than the mean peak pressure for all bars at $25 \mathrm{~mm}$ radial ordinate. The peak specific impulse recorded at the $+y 25 \mathrm{~mm}$ bar in test 5 was $3.63 \mathrm{MPa} . \mathrm{ms}$, which is $29 \%$ greater than the mean peak specific impulse for all bars at $25 \mathrm{~mm}$ radial ordinate.

This variability is evidence of the growth of local irregularities due to Rayleigh-Taylor [56, 57] and RichtmyerMeshkov [58, 59] instabilities on the surface of the expanding detonation product cloud. It is hypothesised that the blast wave from the (extremely near-field) spherical charges in tests 1-3 impinges on the target before these instabilities have formed to any significant degree, whereas in the cylindrical tests (4-6), where there is a greater physical and scaled distance between the charge and the target, these instabilities become more prominent [15].

\section{Effect of charge casing}

Figure 7 shows the compiled peak specific impulses (and mean distribution) from test 7 compared to the mean distribution from tests 4-6. Whilst the epicentral impulse for test 7 appears to be slightly below the average from tests 4 6 , it is worth noting that this value comes from only one data point and hence some degree of experimental spread should be expected, given the growth of instabilities mentioned previously. There is very little difference between the test 4-6 impulse distribution and test 7 impulse distribution at distances greater than $25 \mathrm{~mm}$ from the target centre. Therefore it can be said that, for this geometry, the influence of a $3 \mathrm{~mm}$ thick PVC charge case is negligible.

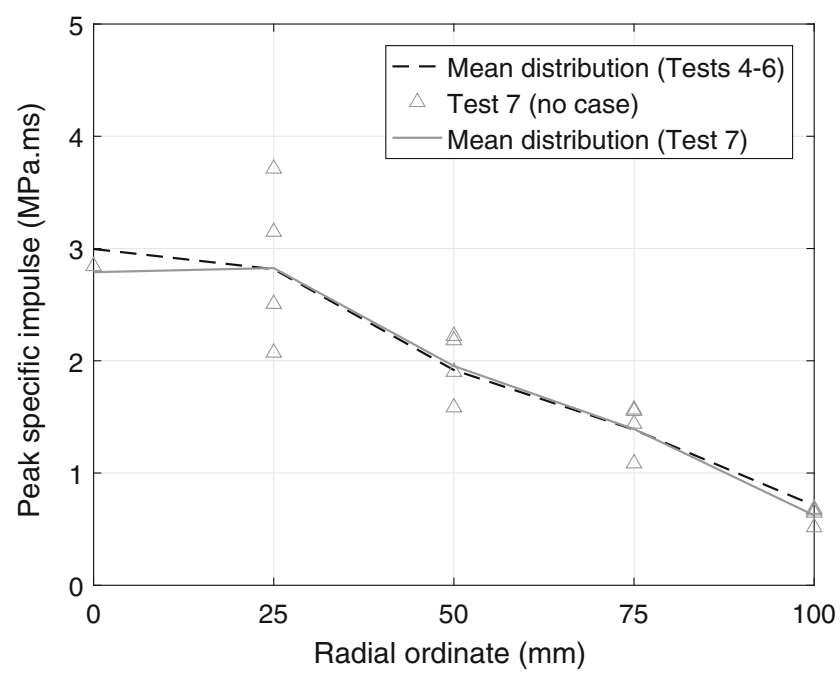

Fig. 7 Comparison of compiled peak specific impulse for Test 7 (no case) and Tests 4-6 (3 mm thick PVC case with lid removed)

\section{Interpolated impulse distribution}

A spline interpolant was fitted to the values of mean peak specific impulse at each radial ordinate for clarity of presentation and to aid future numerical model validation.

Three conditions were applied to the fit: zero gradient at the plate centre; zero gradient and zero impulse at an arbitrary large radial offset from the plate centre; and non-negative peak specific impulse at any radial ordinate. These conditions ensured the spline interpolant was physically valid, i.e. radially symmetrical and monotonically decreasing with increasing distance from the plate centre. Figure 8 shows fitted interpolants for both charge arrangements. Integrating these curves with respect to area gives
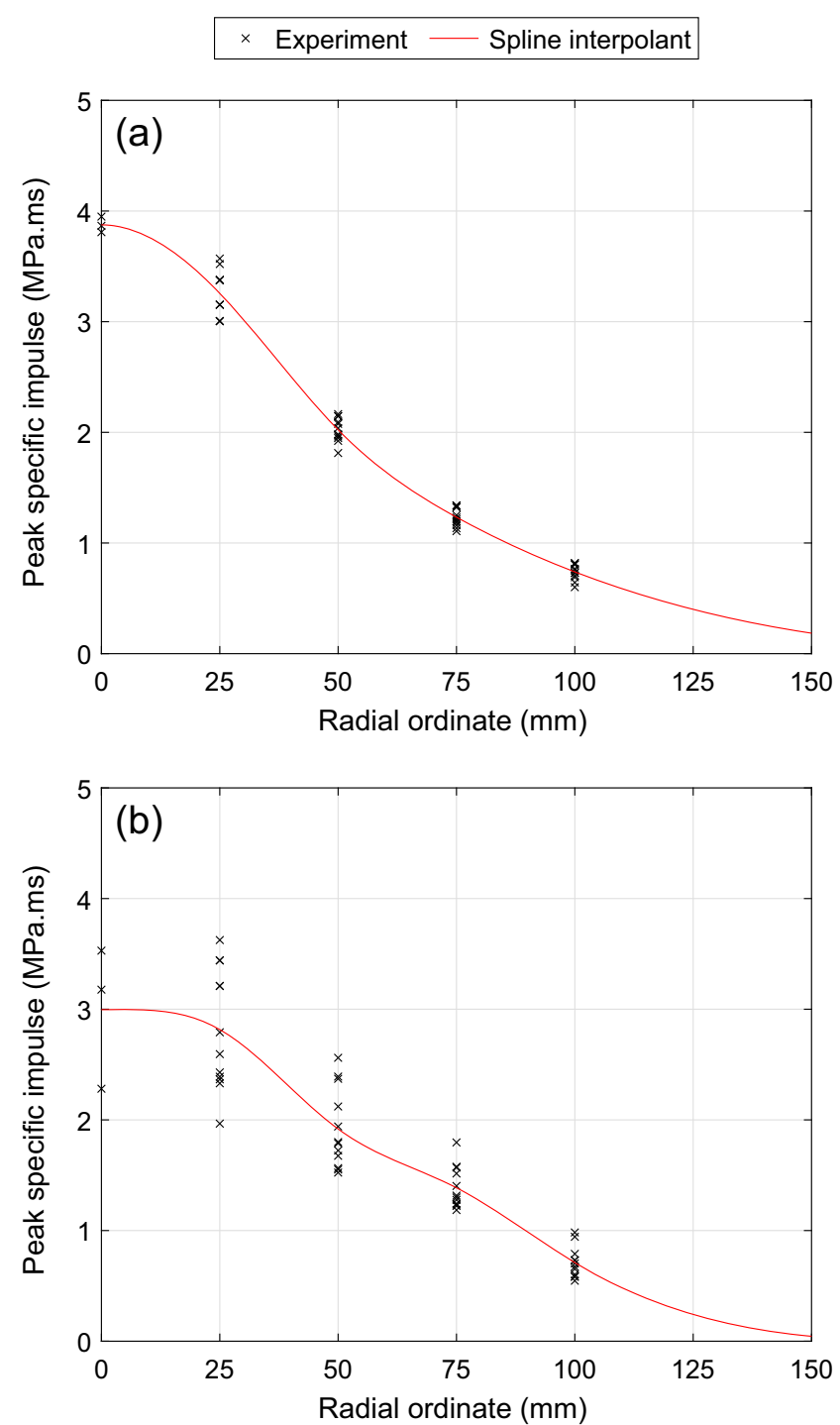

Fig. 8 Compiled peak specific impulse at each bar location with fitted spline interpolant extending beyond instrumented region: (a) Tests 13 (100 g sphere at $55.4 \mathrm{~mm}$ clear stand-off); (b) Tests 4-6 (78 g 3:1 cylinder at $168.0 \mathrm{~mm}$ clear stand-off) 

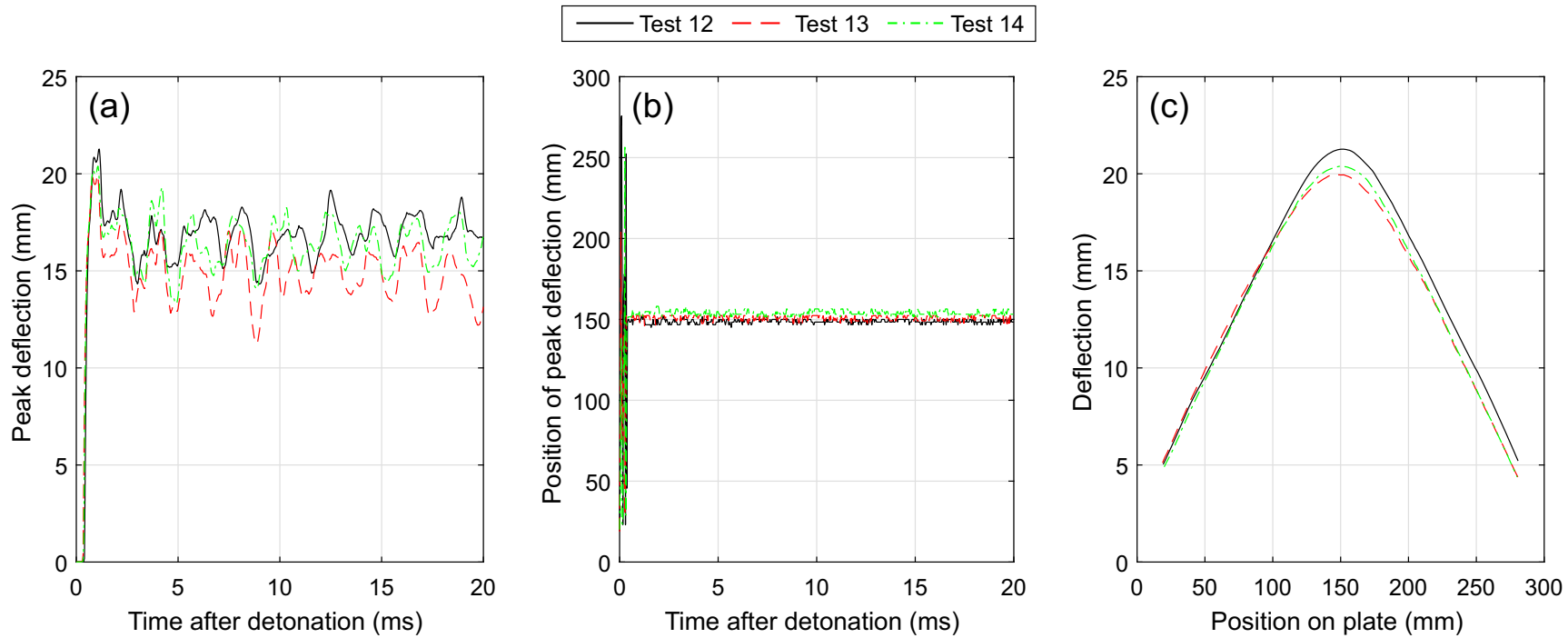

Fig. 9 UCT spherical tests; (a) peak deflection vs time, (b) position of peak deflection vs time, and (c) plate profile at peak deflection

83.9 Ns and 71.3 Ns for spherical and cylindrical charge tests respectively.

\section{Transient Plate Deformation and Global Impulse Measurements}

\section{Dynamic deformation}

Figures 9 and 10 show the results from the spherical and cylindrical UCT tests respectively. Here, Figs. 9(a) and 10(a) show the magnitude of peak deflection vs time, and Figs. 9(b) and 10(b) show the position on the plate where maximum deflection occurs. As $150 \mathrm{~mm}$ corresponds to the plate centre, a point of maximum deflection that differs from $150 \mathrm{~mm}$ indicates a level of asymmetry in the plate response. Figures 9(c) and 10(c) show the displacement profile of the plates at the time of peak deflection. The DIC software was unable to determine any displacements between 6.6-6.9 ms after detonation in test 15 due to debris obscuring the cameras' view of the test plate. However, this data drop-out occurs after the peak deflection is reached and hence the results are unaffected.

Generally the spherical peak deflection profiles and histories are all in good agreement, with peak deflections occurring near the centre for all tests. The cylindrical tests appear less consistent, with test 15 demonstrating a considerably lower peak deflection (which also occurs some $15 \mathrm{~mm}$ from the plate centre), and a marked difference
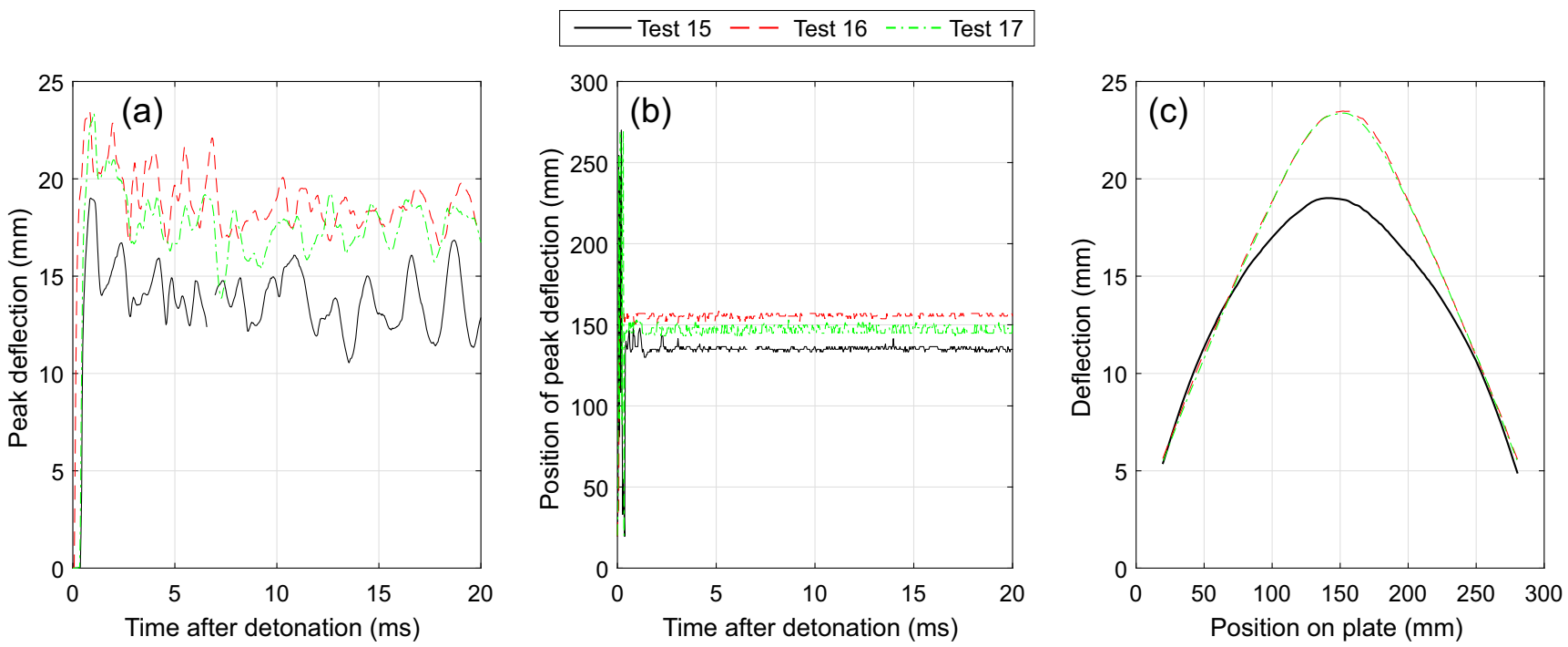

Fig. 10 UCT cylindrical tests; (a) peak deflection vs time, (b) position of peak deflection vs time, and (c) plate profile at peak deflection 


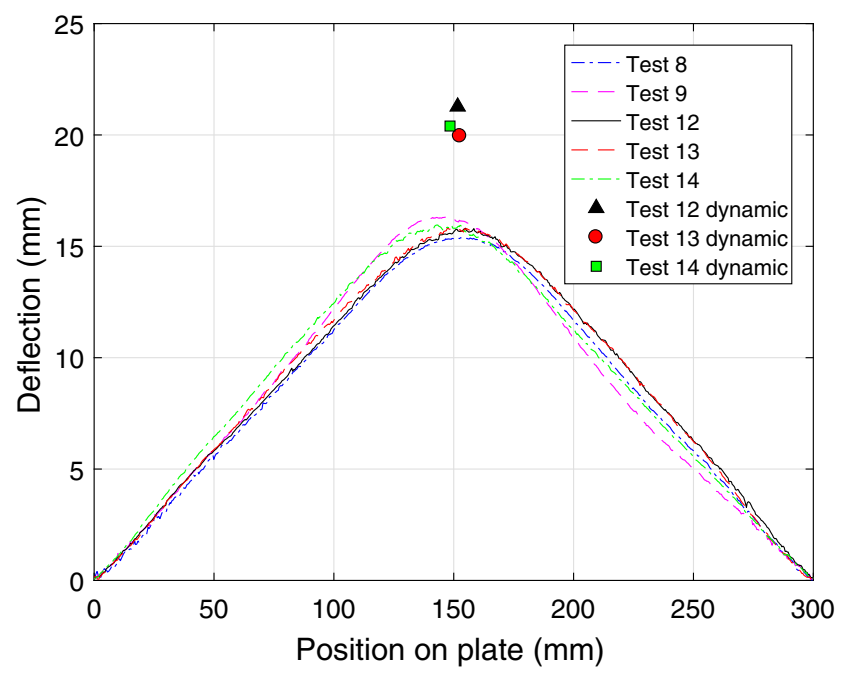

Fig. 11 Residual plate profiles and peak dynamic deflections for UCT spherical tests

in the deflected shape at peak deflection. The observed $15 \mathrm{~mm}$ offset is significantly outside the tolerance on charge geometry and placement, and hence this discrepancy is likely due to an inherent feature of the explosive itself, rather than experimental error. This will be discussed further in "Discussion".

\section{Imparted impulse and residual deformation}

The deformed plates were scanned using a NextEngine Desktop 3D Laser Scanner and post-processed in MatLab. Residual deflection profiles are shown in Figs. 11 and 12 for spherical and cylindrical shots respectively, with peak dynamic deflections plotted in the positions in which they occur for tests where DIC was used. Peak residual and

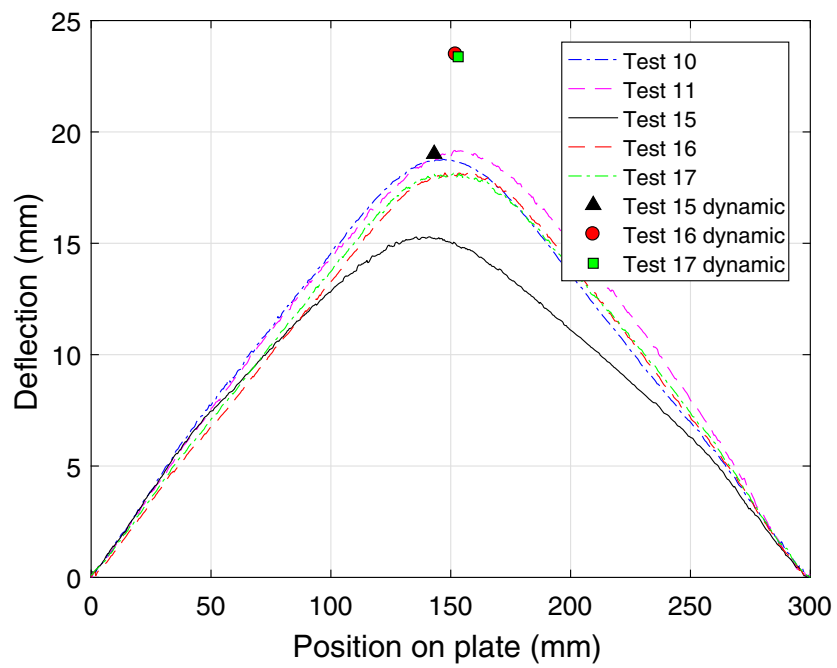

Fig. 12 Residual plate profiles and peak dynamic deflections for UCT cylindrical tests dynamic deflections are summarised in Tables 3 and 4 along with the imparted impulse determined from the recorded pendulum motion. Bonorchis and Nurick [60] demonstrated, through numerical analysis, that for a similar test arrangement to that desrcibed in this article, the impulse acting on the exposed area of the plate was typically $\sim 67 \%$ of the total impulse recorded by the UCT blast pendulum. This factor was found to be insensitive to scaled distance, and hence is used in this article to estimate the total impulse acting on the pate.

The mean recorded impulses are $66.0 \mathrm{Ns}$ and $67.1 \mathrm{Ns}$ for the spherical and cylindrical shots respectively. That the impulses are comparable despite the cylindrical charges being places three times further (clear distance) from the target plate demonstrates the increased directionality caused by the charge shape; an effect recently discussed by Nurick et. al [61]. The spread of experimental impulses is slightly lower for the spherical charges than for the cylindrical charges; all spherical recorded impulses are within $\pm 3.5 \%$ and all cylindrical recorded impulses within $\pm 6.0 \%$ of the respective means. It cannot be said for certain whether this increased variability for the cylinders is significant owing to a small dataset (only five global impulses per configuration), however it is clear that the variability in global impulse uptake is considerably less than the variability in specific impulse seen in "Direct Load Measurements".

The mean values of peak residual and peak dynamic deflections are $15.86 \mathrm{~mm}$ and $20.54 \mathrm{~mm}$ for the spheres and $17.91 \mathrm{~mm}$ and $21.96 \mathrm{~mm}$ for the cylinders. The peak residual and peak dynamic deflections recorded in test 15 are considerably lower than all other cylindrical tests, despite the global impulse closely matching the mean value from the test series. It is suggested that this discrepancy is caused by non-coaxial impingement of the shock wave and detonation products, likely due to instabilities emerging from the detonation product/air interface, which gives reason for the lower magnitude and non-central peak (dynamic and residual) deformation. This is justified with reference to Fig. 6(b) where the maximum peak specific impulse at $25 \mathrm{~mm}$ from the plate centre in test 5 was $21 \%$ greater than the mean central bar peak specific impulse and $16 \%$ greater than the peak central bar specific impulse for that test. It is possible that a similar situation occurred in test 15 and the maximum peak specific impulse was acting some distance from the plate centre.

\section{Plate velocity profiles}

Figure 13 shows the displacement-time history along the centreline of the plate, recorded from test 12. Figure 14 shows the velocity-time history along the centreline of the plate for the same test, assuming a linear gradient between displacement profiles. It can be seen that peak displacement 
Table 3 Impulse and deflection results from spherical UCT tests

\begin{tabular}{llllll}
\hline Test no. & Explosive shape & Impulse (Ns) & Factored impulse (Ns)* & Residual deflection (mm) & Dynamic reflection (mm) \\
\hline 8 & sphere & 65.5 & 43.9 & 15.39 & - \\
9 & sphere & 68.3 & 45.8 & 16.31 & - \\
12 & sphere & 65.8 & 44.1 & 15.81 & 21.27 \\
13 & sphere & 66.1 & 44.3 & 15.82 & 19.95 \\
14 & sphere & 64.3 & 43.1 & 15.96 & 20.40 \\
& mean & 66.0 & 44.2 & 15.86 & 20.54 \\
\hline
\end{tabular}

*denotes impulse acting on the exposed area of the plate has been estimated by factoring the total impulse by 0.67 , after [60]

Table 4 Impulse and deflection results from cylindrical UCT tests

\begin{tabular}{llllll}
\hline Test no. & Explosive shape & Impulse (Ns) & Factored impulse (Ns)* & Residual deflection (mm) & Dynamic reflection (mm) \\
\hline 10 & cylinder & 71.1 & 47.6 & 18.77 & - \\
11 & cylinder & 65.4 & 43.8 & 19.17 & - \\
15 & cylinder & 67.0 & 44.9 & 15.29 & 19.01 \\
16 & cylinder & 68.8 & 46.1 & 18.17 & 23.48 \\
17 & cylinder & 63.4 & 42.5 & 18.15 & 23.38 \\
& mean & 67.1 & 45.0 & 17.91 & 21.96 \\
\hline
\end{tabular}

*denotes impulse acting on the exposed area of the plate has been estimated by factoring the total impulse by 0.67 , after [60]

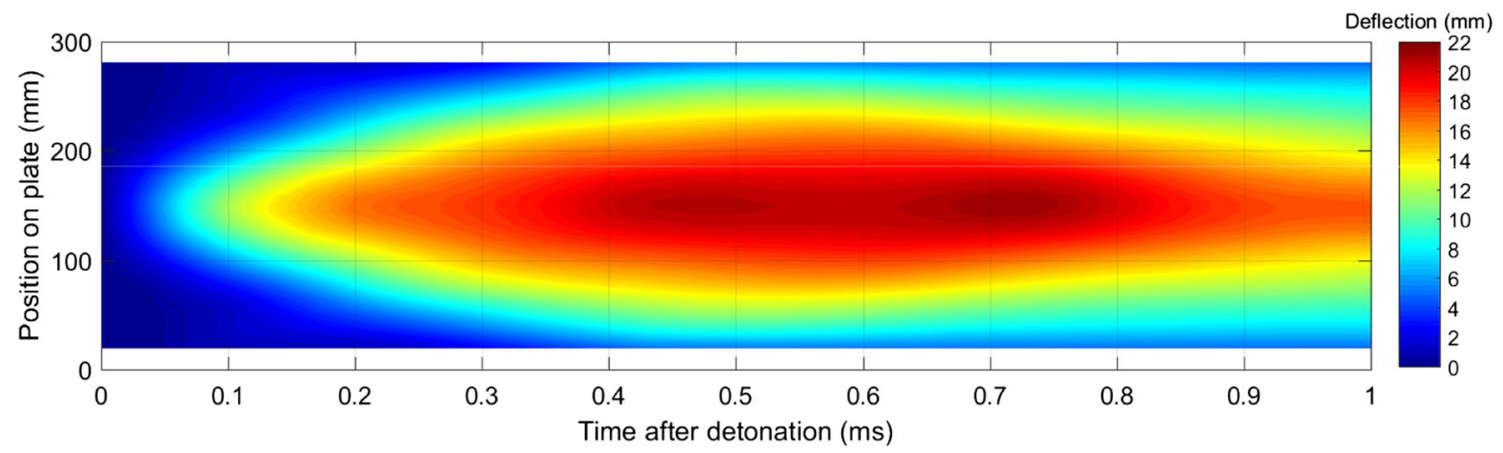

Fig. 13 Plate deformation profile for test 12

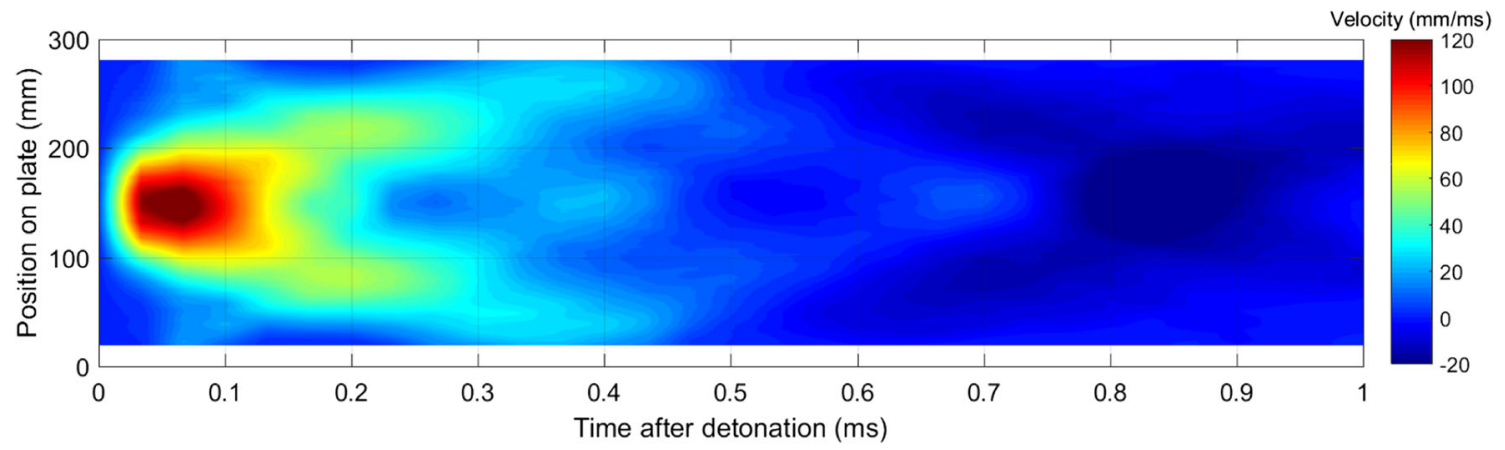

Fig. 14 Plate velocity profile for test 12 
is reached approximately $0.73 \mathrm{~ms}$ after detonation, whereas peak plate velocity is reached approximately $0.06 \mathrm{~ms}$ after detonation. At this time, the plate has displaced a relatively small amount compared with the peak value, and deformation is concentrated towards the central $\sim 100 \mathrm{~mm}$ diameter region of the plate. This suggests that the work done by the blast load is small and hence the system is responding largely in the impulsive domain.

Two sets of flexural waves can be observed in the velocity-time history in Fig. 14: one set beginning shortly after arrival, propagating inwards from the edges of the plate; and one set beginning shortly after peak velocity is reached, propagating outwards from the centre of the plate. This behaviour is consistent with flexural waves generated by uniformly distributed and central point loads respectively, and are indicative of the specific impulse distribution seen in Fig. 8(a). Similar behaviour was seen for the cylindrical charge tests, however the results are not repeated here for brevity.

The inward travelling flexural waves can be seen to cross at the plate centre at approximately $0.39 \mathrm{~ms}$ after detonation, indicating a propagation velocity of approximately 400$450 \mathrm{~mm} / \mathrm{ms}$. After crossing, the magnitude of the waves appears to diminish and they are subsequently difficult to distinguish at the current plotting resolution. The outward travelling flexural waves reach the edge of the plates at approximately $0.4-0.45 \mathrm{~ms}$ after detonation where they are reflected inwards and cross at the plate centre at approximately $0.68 \mathrm{~ms}$ after detonation. This repeated crossing of flexural waves causes the high frequency oscillatory behaviour seen in Figs. 9(a) and 10(a).

Peak velocity profiles were extracted from postprocessing of the DIC data and are shown in Figs. 15 and 16. Again the spherical velocities demonstrate a high level

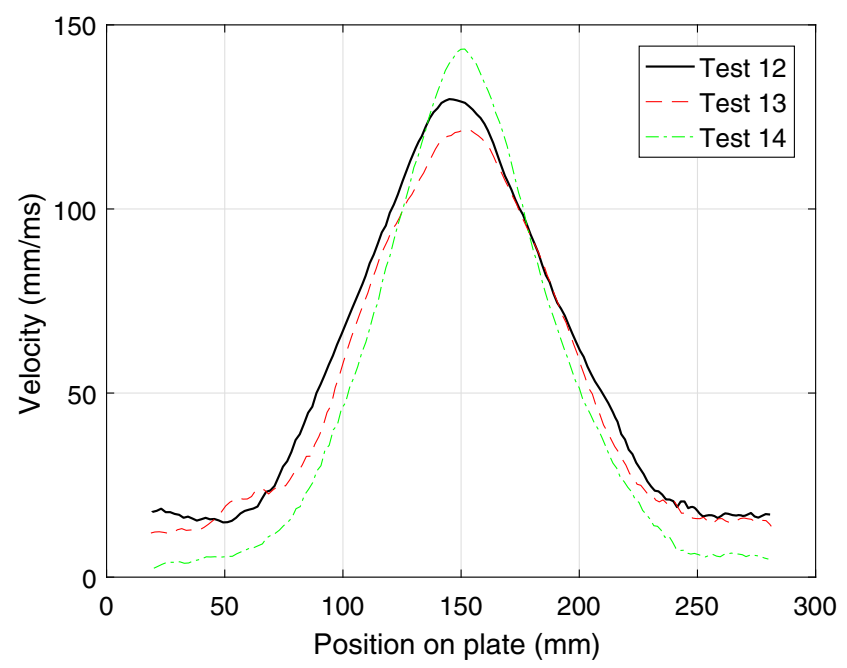

Fig. 15 Peak velocity profiles for spherical tests

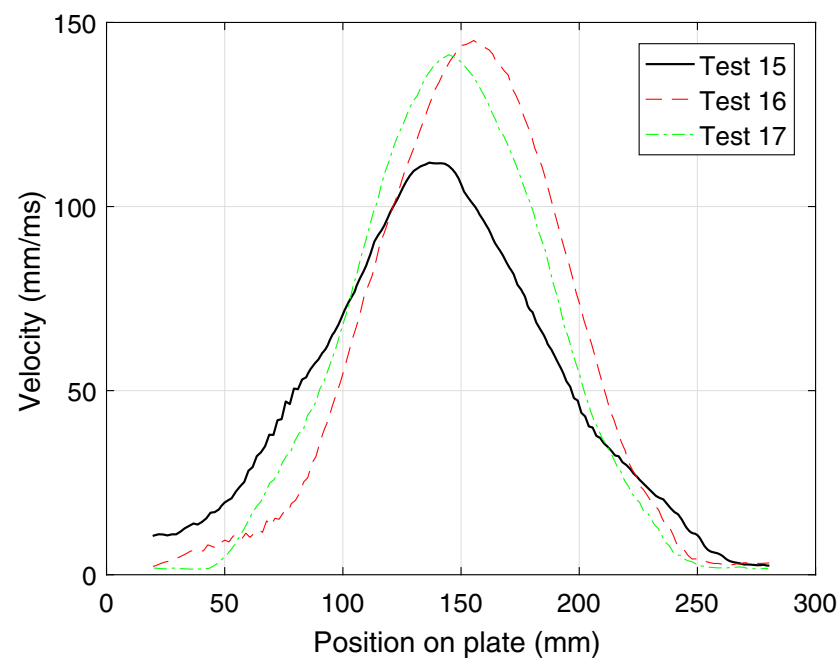

Fig. 16 Peak velocity profiles for cylindrical tests

of consistency. As with the displacement profile, the velocity profile of test 15 appears lower in magnitude and skewed towards the left-hand side of the plot.

\section{Discussion}

\section{Scale Factors}

Using Hopkinson-Cranz scaling [43, 44], we can say that

$\frac{x_{U o S}}{x_{U C T}}=\frac{i_{U o S}}{i_{U C T}}=\sqrt[3]{\frac{W_{U o S}}{W_{U C T}}}$

where $x, i$, and $W$ are distance from the centre of the plate, specific impulse, and charge mass, and the subscripts $U o S$ and $U C T$ refer to quantities used in the University of Sheffield and University of Cape Town tests respectively. In order to compare the UCT results to the UoS results, therefore, we must multiply distances and specific impulses by the cube-root of the mass scale factor: $\sqrt[3]{100 / 50}=$ 1.26 for the spherical tests and $\sqrt[3]{78 / 50}=1.16$ for the cylindrical tests respectively. Furthermore, since total impulse is a product of specific impulse and area, total impulses can be compared by dividing or multiplying by the mass scale factor: 2.00 for spherical tests and 1.56 for cylindrical tests.

\section{Total and Specific Impulse Comparison}

An imparted impulse results in an equivalent change in momentum. Under impulsive loading conditions, therefore, 


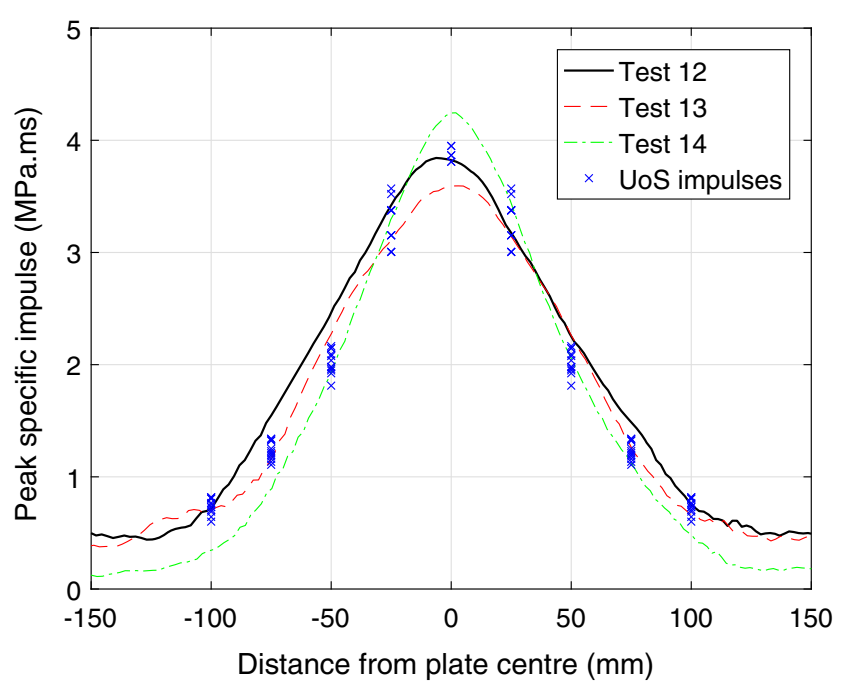

Fig. 17 Measured (UoS) and inferred (UCT) specific impulses from spherical tests, expressed at UoS scale

we should expect the initial velocity profile of the plate, $v(x)$ to be given by

$v(x)=\frac{i(x)}{\rho t}$

where $x$ is distance and $i$ is specific impulse as defined previously, and $\rho$ and $t$ are density and thickness of the plate: $7830 \mathrm{~kg} / \mathrm{m}^{3}$ and $3.00 \mathrm{~mm}$ respectively.

The average factored impulses for the UCT spherical and cylindrical charge tests are 44.2 and 45.0 Ns respectively (Tables 3 and 4). When expressed at UoS scale, by multiplying by the respective mass scale factors, this gives 88.4 and $70.2 \mathrm{Ns}$, which is in very good agreement with the values of 83.9 and 71.3 Ns given in "Interpolated impulse distribution".

Figure 17 shows the inferred specific impulses from the UCT spherical tests calculated from equation (6), expressed at UoS scale using equation (5), compared to the specific impulses directly measured from the UoS spherical tests. Figure 18 shows the same for the cylindrical tests. Here, markers for the UoS test results have been duplicated either side of the plate centre for comparative purposes.

For the spherical tests (Fig. 17), the inferred specific impulses closely match the measured values. This confirms that Hopkinson-Cranz scaling is valid for the scales used in the current testing. While the DIC velocity measurements do not have the same temporal resolution as the UoS Hopkinson bar results, the inferred specific impulses correlate very well and show the same form and magnitude as the directly measured load. For the cases studied in this paper, as there is little difference between the loading measured on a rigid reflecting surface (UoS tests) and a deformable one (UCT tests), it can be said that fluidstructure-interaction [62-64] has negligible influence on the load developed on the reflecting surface.

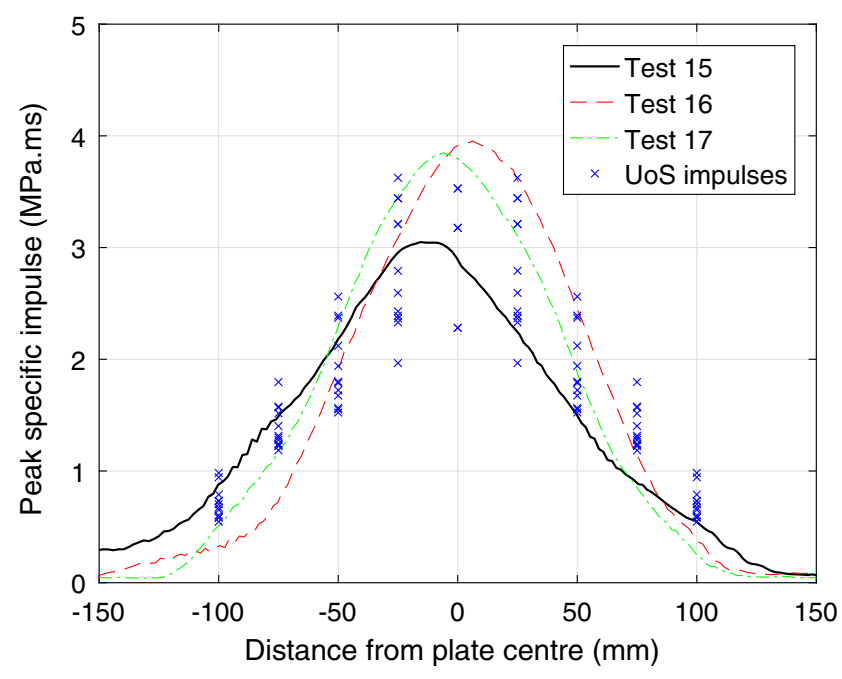

Fig. 18 Measured (UoS) and inferred (UCT) specific impulses from cylindrical tests, expressed at UoS scale

The directly-measured cylindrical specific impulses demonstrated considerably more spread than those in the spherical tests. This increased variability is also borne-out in the inferred specific impulse distributions from the DIC measurements (Fig. 18). Generally, the inferred specific impulses for the cylinder tests lie within the range of recorded specific impulses, and are in particularly good agreement between $\pm 25-50 \mathrm{~mm}$ from the plate centre. When viewed with this dataset, test 15 appears less of an outlier and better fits within the general range of recorded data. In almost all cases, the inferred specific impulse begins to drop below the recorded values at $\pm 100 \mathrm{~mm}$ from the UoS-scale plate centre. This is due to the fact that the loading is not truly impulsive, and when considering initial velocities there is a non-negligible delay between the loading being applied in the plate centre and the loading being applied at the periphery of the plate. The velocity profiles in this article are extracted from one particular instant in time (when the maximum velocity is acting at the centre of the plate), rather than the time-invariant peak velocity at any given point on the plate, however the influence that this has on the inferred impulse distribution appears to be minimal.

\section{Summary and Conclusions}

This paper presents the results from two experimental test series conducted at different scales, and investigated the loading distribution and subsequent dynamic response of plates subjected to near-field explosions. Direct load measurements were performed at the University of Sheffield (UoS), UK, and plate deformation measurements were preformed at the Blast Impact \& Survivability Unit (BISRU) at the University of Cape Town (UCT), South Africa. In 
each series, two different charge configurations were tested: spherical and cylindrical (3:1 diameter:height) PE4 charges. The spherical and cylindrical charges were $100 \mathrm{~g}$ and $78 \mathrm{~g}$ respectively in the UoS tests, and $50 \mathrm{~g}$ for both spheres and cylinders in the UCT tests. Direct load measurements were performed on an effectively rigid target plate, whereas deformation measurements were performed using $3 \mathrm{~mm}$ thick Domex 355MC plates, with fully clamped boundaries and an effective exposed circular area with a $300 \mathrm{~mm}$ diameter.

A significant increase in the directionality of loading was observed for the cylindrical charges. The imparted impulses from spherical and cylindrical charges were similar, despite the cylinders being three times further (clear scaled distance) from the target plate. Whilst the total impulses integrated over the instrumented area (UoS) and entire plate surface (UCT) were highly repeatable for both spherical and cylindrical charges, the specific load distributions demonstrated a considerably higher level of variability in the cylindrical tests. This is hypothesised to be due to a greater relative distance from the charge to the target and hence greater propensity for Rayleigh-Taylor and Richtmyer-Meshkov instabilities to develop.

The plate deformation measurements from the cylindrical charges also demonstrated a higher level of variability relative to the spherical charge plate deformation measurements. This suggests that spatial variations in loading as a result of surface instabilities in the expanding detonation product cloud are significant enough to influence the transient displacement profile of a blast loaded plate.

Initial velocity distributions were calculated from UCT DIC data. Conservation of momentum was used to infer the distribution of specific impulse, and Hopkinson-Cranz scaling was used to express the UoS and UCT tests at the same scale. The inferred impulses from the UCT tests showed excellent agreement with the directly-measured specific impulse distributions from the UoS tests.

Data access statement The data presented in this publication can be obtained on request by contacting sam.rigby@sheffield.ac.uk.

Acknowledgements The authors wish to thank the technical staff at Blastech Ltd. and Mr Shaun Kriek from the University of Cape Town for their assistance in conducting the experimental work reported herein. The first author acknowledges the financial support from the Royal Academy of Engineering Newton Research Collaboration Programme (NCRP1617/6/212).

Open Access This article is distributed under the terms of the Creative Commons Attribution 4.0 International License (http:// creativecommons.org/licenses/by/4.0/), which permits unrestricted use, distribution, and reproduction in any medium, provided you give appropriate credit to the original author(s) and the source, provide a link to the Creative Commons license, and indicate if changes were made.

\section{References}

1. Esparza E (1986) Blast measurements and equivalency for spherical charges at small scaled distances. Int J Impact Eng 4(1):23-40

2. Kingery CN, Bulmash G (1984) Airblast parameters from TNT spherical air burst and hemispherical surface burst. Technical Report ARBRL-TR-02555, U.S Army BRL, Aberdeen Proving Ground, MD USA

3. Dewey JM (1964) The air velocity in blast waves from t.n.t. explosions. Proceedings of the Royal Society of London A: Mathematical, Phys Eng Sci 279(1378):366-385

4. Brode HL (1955) Numerical solutions of spherical blast waves. J Appl Phys 26(6):766-775

5. Rigby SE, Tyas A, Fay SD, Clarke SD, Warren JA (2014) Validation of semi-empirical blast pressure predictions for far field explosions - is there inherent variability in blast wave parameters? In: 6th international conference on protection of structures against hazards (PSH14), Tianjin, China

6. Shin J, Whittaker AS, Cormie D (2015) Incident and normally reflected overpressure and impulse for detonations of spherical high explosives in free air. J Struct Eng 04015057(13):1-13

7. Huffington NJ, Ewing WO (1985) Reflected impulse near spherical charges. Technical report BRL-TR-2678, ballistic research laboratories, MD USA

8. Nansteel MW, Veldman RL, Chen CC, Lawrence W (2013) Impulse plug measurements of blast reflected impulse at close range. Propellants Explosives, Pyrotechnics 38(1):120-128

9. Hopkinson B (1914) A method of measuring the pressure produced in the detonation of high explosives or by the impact of bullets. Philiosophical Transactions of the Royal Society of London. Series A, Containing Papers of a Mathematical or Physical Character 213(1914):437-456

10. Kolsky H (1949) An investigation of the mechanical properties of materials at very high rates of loading. Proc Phys Soc Section B 62(11):676

11. Edwards DH, Thomas GO, Milne A, Hooper G, Tasker D (1992) Blast wave measurements close to explosive charges. Shock Waves 2:237-243

12. Piehler T, Birk A, Benjamin R, Summers E, Aubert S, Boyle V (2009) Near-field impulse loading measurement techniques for evaluating explosive blast. Technical Report ARL-RP-235, Army Research Laboratory, Aberdeen Proving Ground, MD USA

13. Rigby SE, Tyas A, Fay SD, Clarke SD, Warren JA, Elgy I, Gant M (2014) Testing apparatus for the spatial and temporal pressure measurements from near-field free air explosions. In: 6th international conference on protection of structures against hazards (PSH14), Tianjin, China

14. Rigby SE, Tyas A, Clarke SD, Fay SD, Reay J, Warren JA, Elgy I, Gant M (2015) Observations from preliminary experiments on spatial and temporal pressure measurements from near-field free air explosions. Int J Protective Struct 6(2):175-190

15. Tyas A, Reay JJ, Fay SD, Clarke SD, Rigby SE, Warren JA, Pope DJ (2016) Experimental studies of the effect of rapid afterburn on shock development of near-field explosions. Int J Protective Struct 7(3):456-465

16. Cloete TJ, Nurick GN (2016) Blast characterization using a ballistic pendulum with a centrally mounted Hopkinson bar. Int J Protective Struct 7(3):367-388

17. Tyas A, Pope DJ (2003) The energy take-up of panels subjected to near-field blast loading. In: International conference on the response of structures to extreme loading, Toronto, Canada

18. Chung Kim Yuen S, Nurick G (2005) Experimental and numerical studies on the response of quadrangular stiffened plates. Part I: Subjected to uniform blast load. Int J Impact Eng 31(1):5583 
19. Cloete TJ, Nurick GN, Palmer RN (2005) The deformation and shear failure of peripherally clamped centrally supported blast loaded circular plates. Int J Impact Eng 32(1-4):92-117

20. Langdon GS, Chung Kim Yuen S, Nurick GN (2005) Experimental and numerical studies on the response of quadrangular stiffened plates. Part II: localised blast loading. Int J Impact Eng 31(1):85-111

21. Neuberger A, Peles S, Rittel D (2007) Scaling the response of circular plates subjected to large and close-range spherical explosions. Part I: Air-blast loading. Int J Impact Eng 35(5):859-873

22. Neuberger A, Peles S, Rittel D (2007) Scaling the response of circular plates subjected to large and close-range spherical explosions. Part II: Buried charges. Int J Impact Eng 35(5):874-882

23. Chung Kim Yuen S, Nurick GN, Verster W, Jacob N, Vara A, Balden V, Bwalya D, Govender R, Pittermann M (2008) Deformation of mild steel plates subjected to large-scale explosions. Int J Impact Eng 35(8):684-703

24. Safari KH, Zamani J, Khalili SMR, Jalili S (2011) Experimental, theoretical, and numerical studies on the response of square plates subjected to blast loading. J Strain Anal Eng Des 46(8):805816

25. Longère P, Geffroy-Grèze A-G, Leblé B, Dragon A (2013) Ship structure steel plate failure under near-field air-blast loading: Numerical simulations vs experiment. Int J Impact Eng 62:88-98

26. Jones N (2014) Dynamic inelastic response of strain rate sensitive ductile plates due to large impact, dynamic pressure and explosive loadings. Int J Impact Eng 74:3-15

27. Chung Kim Yuen S, Nurick GN, Langdon GS, Iyer Y (2016) Deformation of thin plates subjected to impulsive load Part III an upyear 25 years on. Int J Impact Eng pages -

28. Sutton M, Wolters W, Peters W, Ranson W, McNeill S (1983) Determination of displacements using an improved digital correlation method. Image Vis Comput 1(3):133-139

29. Hargather MJ, Settles GS (2009) Laboratory-scale techniques for the measurement of a material response to an explosive blast. Int J Impact Eng 36(7):940-947

30. Nansteel MW, Chen CC (2009) High speed photography and digital image correlation for the study of blast structural response. Int Test Eval Assoc J 30:45-56

31. Tiwari V, Sutton MA, McNeill SR, Xu S, Deng X, Fourney WL, Bretall D (2009) Application of 3d image correlation for full-field transient plate deformation measurements during blast loading. Int J Impact Eng

32. Spranghers K, Vasilakos I, Lecompte D, Sol H, Vantomme J (2012) Full-field deformation measurements of aluminum plates under free air blast loading. Exp Mech 52(9):1371-1384

33. Genovese K, Casaletto L, Rayas JA, Flores V, Martinez Amalia (2013) Stereo-digital Image Correlation (DIC) measurements with a single camera using a biprism. Opt Lasers Eng 51(3):278285

34. LeBlanc J, Gardner N, Shukla A (2013) Effect of polyurea coatings on the response of curved e-glass/vinyl ester composite panels to underwater explosive loading. Compos Part B: Eng 44(1):565-574

35. Spranghers K, Vasilakos I, Lecompte D, Sol H, Vantomme J (2013) Numerical simulation and experimental validation of the dynamic response of aluminum plates under free air explosions. Int J Impact Eng 54:83-95

36. Zhao X, Tiwari V, Sutton MA, Deng X, Fourney WL, Leiste U (2013) Scaling of the deformation histories for clamped circular plates subjected to blast loading by buried charges. Int J Impact Eng 54:31-50

37. LeBlanc J, Shillings C, Gauch E, Livolsi F, Shukla A (2016) Near field underwater explosion response of polyurea coated composite plates. Exp Mech 56(4):569-581
38. Rijensky O, Rittel D (2016) Polyurea coated aluminum plates under hydrodynamic loading: does side matter? Int J Impact Eng 98:1-12

39. Aune V, Fagerholt E, Hauge KO, Langseth M, Børvik T (2016) Experimental study on the response of thin aluminium and steel plates subjected to airblast loading. Int J Impact Eng 90:106121

40. Curry RJ, Langdon GS (2017) Transient response of steel plates subjected to close proximity explosive detonations in air. Int $\mathbf{J}$ Impact Eng 102:102-116

41. Yao S, Zhang D, Lu Z, Lin Y, Lu F (2018) Experimental and numerical investigation on the dynamic response of steel chamber under internal blast. Eng Struct 168:877-888

42. Kakogiannis D, Verleysen P, Belkassem B, Coghe F, Rabet L (2018) Multiscale modelling of the response of ti-6ai-4v sheets under explosive loading. Int J Impact Eng 119:1-13

43. Hopkinson B (1915) British Ordnance Board Minutes, 13565

44. Cranz C (1926) Lehrbuch der Basllistik. Springer, Berlin

45. Kinney GF, Graham KJ (1985) Explosive shocks in air. Springer, New York

46. Clarke SD, Fay SD, Warren JA, Tyas A, Rigby SE, Elgy I (2015) A large scale experimental approach to the measurement of spatially and temporally localised loading from the detonation of shallow-buried explosives. Meas Sci Technol 26:015001

47. Rigby SE, Tyas A, Bennett T, Fay SD, Clarke SD, Warren JA (2014) A numerical investigation of blast loading and clearing on small targets. Int J Protective Struct 5(3):253-274

48. Rigby SE, Fay SD, Clarke SD, Tyas A, Reay JJ, Warren JA, Gant M, Elgy I (2016) Measuring spatial pressure distribution from explosives buried in dry leighton buzzard sand. Int J Impact Eng 96:89-104

49. Nurick G, Martin J (1989) Deformation of thin plates subjected to impulsive loading - a review Part 2: experimental studies. Int J Impact Eng 8:171-186

50. Rigby SE, Fay SD, Tyas A, Clarke SD, Reay JJ, Warren JA, Gant M, Elgy I (2018) Influence of particle size distribution on the blast pressure profile from explosives buried in saturated soils. Shock Waves 28(3):613-626

51. Bancroft D (1941) The velocity of longitudinal waves in cylindrical bars. Phys Rev 59:588-593

52. Baker WE (1973) Explosions in air. University of Texas Press, Austin

53. Rigby SE, Tyas A, Bennett T, Clarke SD, Fay SD (2014) The negative phase of the blast load. Int J Protective Struct 5(1):1-20

54. Rigby SE, Barr AD, Clayton M (2018) A review of pochhammerchree dispersion in the hopkinson bar. Proceedings of the Institution of Civil Engineers - Engineering and Computational Mechanics 171(1):3-13

55. Tyas A, Watson AJ (2001) An investigation of frequency domain dispersion correction of pressure bar signals. Int J Impact Eng 25(1):87-101

56. Rayleigh L (1882) Investigation of the character of the equilibrium of an incompressible heavy fluid of variable density. Proc Lond Math Soc 4(1):170-177

57. Taylor GI (1950) The instability of liquid surfaces when accelerated in a direction perpendicular to their planes. I. Proceedings of the Royal Society A - Mathematical, Phys Eng Sci 201(1065):192-196

58. Richtmyer RD (1960) Taylor instability in a shock acceleration of compressible fluids. Commun Pur Appl Math 13:297-319

59. Meshkov EE (1969) Instability of the interface of two gases accelerated by a shock wave. Fluid Dyn 4:101-104

60. Bonorchis D, Nurick GN (2009) The influence of boundary conditions on the loading of rectangular plates subjected to localised blast loading - importance in numerical simulations. Int J Impact Eng 36(1):40-52 
61. Nurick G, Mahoi S, Langdon GS (2016) The response of plates subjected to loading arising from the detonation of different shapes of plastic explosive. Int J Impact Eng 89:102-113

62. Kambouchev N, Noels, Radovitzky R (2006) Nonlinear compressibility effects in fluid-structure interaction and their implications on the air-blast loading of structures. J Appl Phys 100(063519):1-11
63. Kambouchev N, Noels L, Radovitzky R (2007) Numerical simulation of the fluid-structure interaction between air blast waves and free-standing plates. Comput Struct 85(11-14):923-931

64. Gauch HL, Montomoli F, Tagarielli VL (2018) On the role of fluid-structure interaction on structural loading by pressure waves in air. Shock J Appl Mech 85(11):111007-1-11 